\title{
Occasional reviews
}

\section{Coal mining and chronic obstructive pulmonary disease: a review of the evidence}

\author{
David Coggon, Anthony Newman Taylor
}

The potential of coal mine dust to cause disabling pneumoconiosis has long been recognised, but research now suggests that pneumoconiosis is not the only respiratory hazard of coal mining. Over the last 30 years evidence has accumulated that miners also experience an excess of chronic obstructive pulmonary disease (COPD), and this has led the British Government to classify chronic bronchitis and emphysema in coal miners as an occupational disease for which industrial injuries benefit can be paid. In Germany, too, COPD in miners is now compensated as an occupational disease. However, some scientists have expressed doubts as to whether coal mine dust can cause clinically important loss of lung function in the absence of complicated pneumoconiosis. ${ }^{1}$ In view of this continuing controversy, it is helpful to review the evidence as it now stands.

The epidemiological investigations that bear on the relation between coal mining and COPD are of four main types: (1) studies comparing lung function in miners and nonminers; (2) studies of the patterns of symptoms and lung function in miners according to their exposure to coal mine dust; (3) analyses of mortality from COPD in relation to coal mining; and (4) analyses of the relation between emphysema in coal miners at necropsy and their previous exposure to dust. In addition, investigations in the laboratory provide information about the toxicological mechanisms whereby coal mine dust might cause obstructive lung disease.

MRC Environmental Epidemiology Unit, University of Southampton, Southampton SO16 6YD, UK

D Coggon

Department of Occupational and Environmental Medicine, Imperial School of Medicine at National Heart and Lung Institute, London SW3 6NP, UK

A Newman Taylor

Correspondence to: Professor D Coggon. single colliery with that of a control group of telecommunication workers from the same locality. ${ }^{3}$ More of the miners than controls reported symptoms of chronic bronchitis (31\% versus $5 \%$ ) and their lung function also tended to be worse. Some $20 \%$ had a forced expiratory volume in one second $\left(\mathrm{FEV}_{1}\right)$ less than $80 \%$ of that predicted for their age and height, compared with only $10 \%$ of the controls. This difference was apparent both in smokers and non-smokers.

In Belgium, Nemery and colleagues carried out a cross sectional comparison of 32 non-smoking coal miners and 34 non-smoking steelworkers. ${ }^{4}$ The miners had significantly lower $\mathrm{FEV}_{1}$ values and maximum expiratory flow rates, and significantly higher residual volumes. However, it is not clear from the published report whether the subjects studied represented a complete sample of those eligible for inclusion in the investigation and, although the miners were some two years older than the steelworkers, this was not taken into account in the analysis. Also, five of the miners were ex-smokers whereas none of the steelworkers had smoked in the past. Exclusion of the miners who had smoked was said not to alter the findings.

More recently, Lewis and colleagues compared $\mathrm{FEV}_{1}$ values in 1286 miners from seven collieries in the East Midlands of England who did not have pneumoconiosis on chest radiography with 567 men sampled at random from the residents of a local authority area in Nottingham. ${ }^{5}$ After adjustment for age, height and smoking, $\mathrm{FEV}_{1}$ was $155 \mathrm{ml}(95 \% \mathrm{CI} 74$ to $236 \mathrm{ml}$ ) lower in the miners than in the controls, the difference being greatest in younger men. The proportion of miners reported as having never smoked $(53.8 \%)$ was surprisingly high, however, suggesting that there may have been some misclassification of their smoking in the analysis. If present, this misclassification would have tended to exaggerate any deficit of lung function in the miners.

A weakness of all of these studies comparing miners and non-miners is their inability to control completely for possible confounding by non-occupational influences on lung function. In particular, the miners examined may have had different lung function from their controls even before they entered the mining industry. 
Such selection effects are less of a concern in studies that have compared lung function within miners according to their exposure to dust.

\section{Symptoms, lung function and dust exposure in coal miners}

Studies of the relation between respiratory symptoms, lung function and exposure to respirable coal mine dust have been carried out in Britain, the United States, Italy and Germany.

\section{THE PFR PROGRAMME}

In Britain data come mainly from the Pneumoconiosis Field Research (PFR) programme conducted by the Institute of Occupational Medicine. ${ }^{6-12}$ This was based on 24 collieries. At an initial survey during 1953-58 more than 30000 miners were examined and repeat surveys were subsequently carried out at approximately five yearly intervals. After the third survey conducted during 1963-68 examinations were discontinued at 14 of the 24 collieries, but all 24 were again included in a follow up survey carried out during 1974-80. This focused on a sample of 17738 miners examined in the first survey (all those with pneumoconiosis and half of the remainder), and aimed to re-examine all survivors, whether or not they were still employed in the coal industry. Information collected at the surveys included details of smoking habits, occupational history and symptoms (elicited by questionnaires), chest radiographs and measurements of lung function (lung function was only assessed in the second and later surveys). Detailed monitoring of exposures to respirable dust was carried out for 10 years between the first and third surveys and continued at the 10 collieries that remained under closer supervision. Many reports have been written on this programme of research, but several are particularly relevant.

Rae and colleagues analysed data on 4122 men from 20 collieries who had been working at the coal face at the time of the first two surveys, and worked either at the coal face or elsewhere underground at the time of the third survey. ${ }^{6}$ Individual cumulative exposures to respirable dust up to the time of the third survey were estimated from job histories and from the measurements of dust levels by job that had been made during the first 10 years of the programme. The contribution from work before the start of the PFR was approximated by the product of the man's average annual exposure during the first five years of the programme and the number of years he had worked previously at the coal face or on development in coal or stone (the most dusty jobs). After exclusion of 127 men whose respiratory symptoms were deemed unreliable, a statistically significant association was found at younger ages between the presence of bronchitic symptoms at the third survey and increasing exposure to dust. This applied both in smokers and nonsmokers. In the older age groups, however, no clear trend was apparent.
Subsequently, Rogan and colleagues examined the relation between $\mathrm{FEV}_{1}$ at the third survey and cumulative dust exposure in the same sample of 4122 men but this time with exclusion of those who had progressive massive fibrosis, were ex-smokers, or were under 25 or over 65 years of age. ${ }^{7}$ After these exclusions, 3581 men were available for analysis. In both smokers and non-smokers there was a reduction in $\mathrm{FEV}_{1}$ with increasing dust exposure in almost all age groups. Multiple regression analysis indicated an average $\mathrm{FEV}_{1}$ loss of $100 \mathrm{ml}$ in relation to the mean dust exposure of the group studied, but with greater losses at younger than at older ages. The reduction in $\mathrm{FEV}_{1}$ associated with dust was greatest in men with the most severe bronchitic symptoms, but was apparent even in those with no bronchitic symptoms.

Love and Miller analysed changes in $\mathrm{FEV}_{1}$ in 1677 miners from five collieries who participated in the second, third and fourth of the PFR surveys and who did not have radiological changes of progressive massive fibrosis (PMF) at any of the three surveys. ${ }^{8}$ (In their paper Love and Miller refer to the surveys as "first", "second" and "third", but this was a simplification for readers who were not familiar with the PFR in its entirety.) After statistical adjustment for the effects of height, smoking, age, and differences between collieries, the decline in $\mathrm{FEV}_{1}$ over approximately 11 years of follow up was greater in those with higher dust exposure before the start of follow up. Thus, a cumulative dust exposure of $117 \mathrm{ghm}^{-3}$ before the second survey was associated with an estimated additional reduction of $42 \mathrm{ml}$ in $\mathrm{FEV}_{1}$ over the next 11 years. This compared with an average extra loss of $122 \mathrm{ml}$ associated with smoking. Loss of $\mathrm{FEV}_{1}$ was not, however, significantly related to concurrent dust exposure during the 11 year follow up period except when colliery differences were ignored.

Soutar and Hurley analysed data on 4059 men who participated in both the first and third surveys and also in the later follow up survey and who did not have radiological changes of PMF at either the third or the follow up survey. ${ }^{9}$ Lung function at the time of the follow up survey was related to cumulative exposure to respirable dust up to that time. After adjustment for age, height, weight, smoking and region, increasing cumulative exposure to dust was associated with lower $\mathrm{FEV}_{1}$. Overall, the estimated reduction in $\mathrm{FEV}_{1}$ was 0.76 $\mathrm{ml}$ per $\mathrm{ghm}^{-3}$ exposure to respirable dust. The relation of dust to $\mathrm{FEV}_{1}$ was clearly apparent in smokers, ex-smokers and non-smokers, and if anything the associated reduction in lung function was somewhat greater in non-smokers than in smokers. The estimated effect of dust did not appear to be sensitive to the way in which smoking was included in the analysisfor example, with or without allowance for an interaction between smoking habit and age. Moreover, it was of similar magnitude in the subset of 2877 men who did not have pneumoconiosis at the time of the follow up survey. There was, however, evidence of a greater effect of dust in the subset of men who had left 
the coal industry before normal retirement age, had taken other jobs, and reported symptoms of chronic bronchitis at follow up, particularly if they were ex-smokers. The authors interpreted this as evidence that exposure to respirable dust can occasionally cause severe respiratory impairment in the absence of PMF.

Marine and colleagues analysed data from the third survey for 3380 men who were aged less than 65 years at the time, who did not have PMF, who had participated in each of the first three surveys, and who smoked cigarettes or were non-smokers. ${ }^{10}$ The sample was much the same as that analysed by Rogan, but with exclusion of those who smoked only pipes or cigars. Predicted values for $\mathrm{FEV}_{1}$ by age and height in the absence of dust exposure were derived from an analysis of a subset of 451 lifetime non-smokers who did not have symptoms of chronic bronchitis. Cumulative exposure to respirable dust up to the time of the third survey (estimated from job histories and dust measurements) was related to risk of four end points: $\mathrm{FEV}_{1}$ less than $80 \%$ predicted; symptoms of chronic bronchitis; symptoms of chronic bronchitis and $\mathrm{FEV}_{1}$ less than $80 \%$ predicted; and $\mathrm{FEV}_{1}$ less than $65 \%$ predicted. In both smokers and non-smokers odds ratios for all end points increased with cumulative exposure to dust such that the risk was generally more than doubled for high exposure $\left(348 \mathrm{ghm}^{-3}\right.$ ) at age 47 . In particular, this doubling of risk was found for $\mathrm{FEV}_{1}$ less than $65 \%$ predicted in both smokers and nonsmokers. In smokers, however, there was an interaction between dust exposure and age, with lower odds ratios at older ages.

Research continued through to the early 1980s at three of the collieries in the PFR - one in South Wales, one in Yorkshire, and one in the North-East. ${ }^{11}$ During 1981-6 a random sample of men who had worked at these pits at any time since 1970 were invited to attend a further medical survey. A total of 1671 were examined, including 604 who had since left the industry and some with PMF. Predicted values for $\mathrm{FEV}_{1}$ in non-smokers with zero dust exposure were derived for each colliery from linear regression models and logistic regression was then used to explore factors influencing the probability of a $942 \mathrm{ml}$ deficit in $\mathrm{FEV}_{1}$ (the mean reduction in men who reported having to stop for breath when walking at their own pace on level ground). After adjustment for smoking and employment status, cumulative dust exposure was associated with an increased risk of this deficit in South Wales (odds ratio for a 100 $\mathrm{ghm}^{-3}$ increase in dust exposure 1.6, 95\% CI 1.3 to 2.0 ) but not at the other two collieries. At the Yorkshire pit, however, there was a strong correlation between age and lifetime dust exposure (correlation coefficient $=0.801$ ), making it difficult to disentangle the effects of age and exposure on lung function.

These investigations from the PFR were carefully planned and executed, but they have several possible weaknesses. One concern is the representativeness of the men studied. To enter the PFR programme miners had to be in employment at the time of a survey, and some miners with more severe respiratory disease may have been excluded because they had already left the industry as a consequence of their ill health. Such selection is particularly likely in the investigations reported by Rae, Rogan and Marine, where subjects had to have been working at the coal face at each of the first two surveys and still be employed underground at the time of the third. Even in the study by Soutar and Hurley, which included men who had left the industry, there was still scope for bias from exclusion of those who had died before the follow up survey, who could not be contacted, or who declined to take part. Such selection effects would only be important, however, if the associations that were found with dust exposure were substantially different in the men studied from those excluded. There is no obvious reason why the relation of symptoms and lung function to dust should have been weaker in those omitted from investigation.

Another limitation is the uncertain validity of the exposure estimates on which the analyses were based. The estimates were derived from occupational histories and from representative dust measurements, but the latter were not available for all time periods and some extrapolation was necessary. Reassuringly, exposures as estimated were found to correlate with severity of pneumoconiosis on radiography, ${ }^{12}$ but inevitably errors will have occurred. Unless these errors were related systematically to symptoms or lung function-for example, exposures were substantially overestimated in miners with low $\mathrm{FEV}_{1}$ compared with those with high $\mathrm{FEV}_{1}$ - the effect will have been to obscure associations with health effects.

It is possible that the mass concentration of respirable dust is not the most relevant index of exposure in relation to COPD. In particular, risk of bronchitis may be influenced also by larger particles which deposit in the bronchi. Use of an imperfect exposure metric would again tend to weaken associations with health outcomes.

A further weakness is the potential for errors in smoking histories. Inaccurate data on smoking could inflate the apparent effects of dust in two circumstances. Firstly, if smoking confounded the association between dust and respiratory disease-that is, men with high exposure to dust tended to smoke more heavily than those with low exposure - failure to assess smoking accurately would lead to incomplete control of the confounding effect in the analysis. Secondly, if smoking were underestimated more or overestimated less in miners with high compared with low exposure to dust, some of the adverse effects of smoking in the miners with high dust exposure would be wrongly attributed to dust. However, the published analyses suggest that smoking was not importantly associated with dust exposure, and there is no plausible reason why men with higher dust exposure should have answered questions about smoking differently from those with lower exposure.

The classification of smoking was relatively crude in most of the analyses. Current, 
ex-smokers and non-smokers were distinguished, but usually no account was taken of the amount smoked. However, where attempts were made to quantify smoking in more detail, the results were virtually unaltered, suggesting that this was not a major source of error.

Another possible source of error was the measurement of health outcomes. Rae excluded some men from his analysis because their report of symptoms was thought to be unreliable (they described persistent cough and phlegm at the time of the second survey but not at the third), but there is no guarantee that symptoms were recorded accurately for the remainder. Nor are $\mathrm{FEV}_{1}$ measurements completely reliable. Particular problems were encountered at the second survey when spirometric testing was first introduced, and these led to the data from most of the collieries being discarded as untrustworthy. Provided that they were random and not biased in relation to exposure, errors in the assessment of $\mathrm{FEV}_{1}$ would tend to reduce the statistical precision with which the effects of dust were estimated, but they would not spuriously exaggerate exposure-response relations. Errors biased in relation to exposure could perhaps arise if there were systematic differences between pits, but the effects of such systematic differences should be eliminated in analyses that controlled for pit or were restricted to one pit.

US NATIONAL STUDY OF COAL WORKERS' PNEUMOCONIOSIS

Rather similar to the PFR programme is the National Study of Coal Workers' Pneumoconiosis (NSCWP) carried out in the United States. ${ }^{13-18}$ This began in 1969 with surveys at 31 nationally distributed mines. Three further rounds of surveys were carried out up to 1988 , the last of which targeted current or ex-miners who had participated in one or both of the first two rounds of surveys. The information collected at the surveys included chest radiographs, measurements of lung function, and details of symptoms, occupational history and smoking habits. Exposures to respirable dust were estimated from occupational histories and dust measurements, but the latter were made mainly to check compliance with legal limits, and not specifically for the purpose of the NSCWP. Several of the investigations carried out within the programme are particularly relevant.

In an early analysis based on the first round of surveys, Morgan and colleagues found decrements in $\mathrm{FEV}_{1}$ and forced vital capacity (FVC) in relation to years worked underground among non-smoking miners who did not have complicated pneumoconiosis. ${ }^{13}$ However, the trend was inconsistent between regions and they dismissed it as inconsequential. Assessment of dust exposure was not possible at this time.

Subsequently, Attfield analysed changes in lung function over nine years in 1072 men aged 20-49 who participated in both the first and third rounds of surveys. ${ }^{14}$ After adjustment for age, height, smoking and the mine where men had worked, there was a decline in $\mathrm{FEV}_{1}$ between the two surveys in association with each of: work at the coal face; increasing number of years between the surveys spent working underground; increasing estimated average exposure to dust between the two surveys; and increasing years of work underground before the initial survey. However, with the numbers of men studied, statistical confidence was limited. The extent of the decline in $\mathrm{FEV}_{1}$ associated with previous underground work was broadly consistent with the effect of previous dust exposure estimated by Love and Miller in Britain. ${ }^{8}$

Attfield and Hodous related lung function at the first survey in 7139 white miners aged 25 years or older to cumulative dust exposure up to the time of the examination. ${ }^{15}$ After adjustment for age, height, region and smoking, exposure to dust was associated with lower $\mathrm{FEV}_{1}$, the estimated reduction being $0.69 \mathrm{ml}$ per ghm $^{-3}$. The reduction was greater in neversmokers and ex-smokers than in current smokers, but this difference could easily have occurred by chance. A similar relation was found in the subset of 4913 miners who showed no evidence of pneumoconiosis at the time of the examination.

Seixas and colleagues analysed lung function from the fourth round of surveys (carried out during 1985-88) in 1185 male miners who had entered the occupation in or after $1970 .{ }^{16}$ After adjustment for age, height, smoking and racial origin, $\mathrm{FEV}_{1}$ was lower in men with higher cumulative exposure to dust. The strength of the relation $\left(5.5 \mathrm{ml}\right.$ per $\mathrm{mg}$ year per $\mathrm{m}^{3}$ or approximately $3.4 \mathrm{ml}$ per $\mathrm{ghm}^{-3}$ ) was greater than in earlier analyses.

A further investigation concentrating on 977 of the same men who had had measurement of lung function in the second round of surveys confirmed the association of $\mathrm{FEV}_{1}$ with cumulative dust exposure but found no relation of either previous or concurrent exposure to dust with decline in $\mathrm{FEV}_{1}$ between the second and fourth rounds of surveys. ${ }^{17}$ However, when Henneberger and Attfield carried out a similar analysis of 1915 miners who had first worked before 1970, they found a different pattern in that cumulative exposure before entry to follow up was associated with accelerated decline in $\mathrm{FEV}_{1}$ during follow up. ${ }^{18}$

The limitations of the NSCWP are similar to those of the PFR programme. The adjustment for smoking may have been rather better but, on the other hand, the data on exposure were less reliable. Exposure estimates were often based on only a few dust measurements and many of these had been made to check compliance with the law. As such they may reflect worst case rather than typical levels. Furthermore, audit of the measurements indicated that they were frequently inaccurate. ${ }^{19}$ Unless related systematically to lung function, the resultant errors would have tended to obscure associations with COPD.

COAL MINERS IN SARDINIA

Carta and colleagues have recently reported an 11 year follow up of Sardinian coal miners. ${ }^{20}$ 
The mines concerned reopened in 1977 and seven surveys of the miners were conducted between 1983 and 1993. Symptoms of chronic bronchitis, smoking habits, and occupational histories before and after working at the mines were obtained by questionnaire, chest radiographs were taken, and lung function was measured. Exposures to respirable dust were estimated from job histories and industrial hygiene data (static sampling and personal monitoring had been carried out frequently from 1978).

Analysis was restricted to 909 men who had worked in the mines for more than two years and who had taken part in at least three surveys. Only 30 of the men had previously worked in coal or metal mines, and none had pneumoconiosis on chest radiography. With adjustment for age, height, smoking and previous occupation, $\mathrm{FEV}_{1}$ at the first survey attended was negatively associated with previous cumulative exposure to dust. Moreover, there was a subsequent decline in $\mathrm{FEV}_{1}$ during follow up in relation to dust exposure during the follow up period $\left(7.6 \mathrm{ml} /\right.$ year per $\left.\mathrm{mg} \mathrm{m}^{-3}\right)$. Men with higher previous exposure to dust showed a slower decline during follow up. After adjustment for age and smoking, increasing annual exposure to dust was also associated with more frequent onset of chronic bronchitic symptoms during follow up.

Although smaller than the PFR and NSCWP programmes, this Italian investigation has the advantage of focusing on newly recruited miners with less scope for selection bias.

OTHER STUDIES

A review by Oxman and colleagues in 1993 described a study of employed and retired miners from a colliery at Recklinghausen in Germany. ${ }^{21}$ The details are scanty but in a cross sectional analysis of 544 men there was a significant negative association between dust exposure and $\mathrm{FEV}_{1}$ after allowance for age, height, and smoking. In addition, $\mathrm{FEV}_{1}$ declined longitudinally in relation to concurrent dust exposure but this effect was not statistically significant.

In contrast, an analysis of lung function in 3850 miners from the north east of England who were claiming industrial injuries benefit for chronic bronchitis and emphysema found a positive relation between $\mathrm{FEV}_{1}$ and years worked underground. ${ }^{22}$ One weakness of this investigation was the lack of more detailed data on exposure. More important, however, is the possibility that the men studied were not representative of miners in general. For example, it is possible that men with the most severe disease had had to give up work early as a consequence, and therefore had shorter employment than those who were less ill.

\section{Mortality from COPD in relation to coal mining}

Various studies have analysed mortality from COPD in relation to coal mining. Liddell examined the death certificates of men aged 20-64 who died in Britain during 1961, and whose last occupation was recorded on the certificate as coal mining or work with the National Coal Board (NCB), or who were identified as having worked in the coal industry from colliery or NCB pension records. ${ }^{23} \mathrm{~A}$ total of 5362 deaths were analysed and important inconsistencies were found between occupations as recorded on the death certificates and as obtained from NCB records or by questioning relatives. For example, 338 men whose last work was definitely outside the mining industry were nevertheless recorded as coal miners on their death certificates. At the same time 240 men known to have last worked as coal miners were not recorded as such on their certificates.

The pattern of occupational misclassification on death certificates varied according to the cause of death. Thus, among men aged 55-64 the proportion of deaths ascribed to bronchitis was $13.4 \%$ in those certified as miners, but only $12.0 \%$ in those known definitely or thought probably to have been miners from other sources. When only those known definitely to have been miners were considered the proportion was even lower $(11.4 \%)$, but it was still substantially higher than in all occupied and retired men of the same age in England and Wales during 1959-63 (9.3\%). There was a low SMR for bronchitis in active miners compared with the national population, but no corresponding analysis was presented for retired miners.

In the United States, Rockette carried out a cohort study of 23232 miners who comprised a $10 \%$ sample of men covered by the United Mine Workers Health and Retirement Funds on 1 January $1959 .{ }^{24}$ During follow up to the end of 1971 , which was $99.5 \%$ complete, there were 201 deaths from bronchitis or emphysema compared with 167.1 expected from national mortality rates. Mortality from asthma was also increased (32 deaths with 19.4 expected), as was that from lung cancer (352 deaths with 310.9 expected).

Cochrane and colleagues followed up populations from British mining communities and analysed mortality according to subjects' occupations at entry to follow up. ${ }^{25-28}$ The cohort containing the largest number of miners was that from the Rhondda Fach in South Wales, and over 30 years there was a marked excess of deaths from bronchitis among these miners compared with the national population (501 deaths observed with approximately 423 expected). ${ }^{25}{ }^{28}$ However, mortality from bronchitis did not increase in relation to category of pneumoconiosis at the start of follow up. Mortality from lung cancer was lower than expected. Among non-miners from the same population there was a deficit of deaths from bronchitis (32 compared with approximately 41 expected).

In a second community, Staveley in Derbyshire, death rates from respiratory disease were no higher in miners than in other occupations, but the number of deaths in this study was much fewer and less statistical confidence can be placed in the finding. ${ }^{26}{ }^{27}$ Death rates specifically from bronchitis were not reported. 
Miller and Jacobsen studied mortality in 26363 miners from 20 collieries in England and Wales who attended the first PFR survey during 1953-58. ${ }^{29}$ Estimates of cumulative exposure to respirable dust up to the time of the survey were possible for $19550(74 \%)$ of the men. Deaths during follow up to 1980 were ascertained from records held by the Office of Population Censuses and Surveys, 94\% of men being successfully traced. The 1627 untraced men (including 15\% who had emigrated) were excluded from the analysis. Total mortality was lower than in the general population of the same regions, but after allowance for age and length of follow up there was a clear increase in mortality from bronchitis and emphysema in relation to dust exposure. However, no corresponding trend was observed for mortality from lung cancer.

More recently, Coggon and colleagues analysed deaths in coal miners aged $20-74$ as part of a national analysis of occupational mortality for the whole of England and Wales during 1979-80 and 1982-90. ${ }^{30}$ Information about age at death, underlying cause of death, and last full time occupation was obtained from death certificates and was used to derive proportional mortality ratios (PMRs) by cause of death. During the 11 years studied 49660 deaths were recorded in coal miners including 824 from coal workers' pneumoconiosis, 4719 from COPD, and 5747 from lung cancer. Their PMR for COPD in comparison with all occupations of the same social class was 144, while that for lung cancer was 91 . The excess mortality from COPD was fairly uniform across the country and did not correlate with that from pneumoconiosis which was much higher in some coal fields than others.

One weakness of mortality studies is the frequent inaccuracy of causes of death as recorded on death certificates. If errors are non-differential with respect to exposure-for example, they are no different in miners and non-miners-they will tend to obscure any associations that are present. However, where they differ according to exposure they can exaggerate or give rise to spurious associations. A particular concern therefore is the possibility that, in deaths associated with multiple pathology, respiratory disease might be preferentially diagnosed as the underlying cause of death in men known to have worked as coal miners. It is questionable, however, whether such bias could explain excesses of mortality from COPD of the magnitude that have been found in miners, and it is notable that in Coggon's study slate quarrymen, another occupational group known to be at risk of pneumoconiosis, did not have an excess mortality from COPD comparable to that found in coal miners. Furthermore, errors in the cause of death would be unlikely to explain differences in mortality between miners with different dust exposures as reported by Jacobsen.

Another concern is the inaccuracy of occupational information from death certificates. This would not affect the studies where occupation was ascertained from other sources but could, for example, be a problem in the study by Coggon. In Britain death certificates are intended to record the deceased's last full time occupation but it has long been recognised that certain occupations, including coal mining, tend to be over-reported. Such overreporting could produce bias in a proportional mortality study if it were differential with respect to cause of death, and Liddell's study suggests that this may be the case, although only to a limited degree. Thus, among confirmed coal miners he still found an excess of deaths from bronchitis in comparison with the national population. The low mortality from bronchitis in active miners in Liddell's study is almost certainly explained by a "healthy worker effect". Anyone with COPD severe enough to cause death is unlikely to have been fit enough for work in a heavy manual job for some time.

The study by Cochrane's group in South Wales showed an increase in deaths from bronchitis in miners, but no relation to the presence or severity of pneumoconiosis. Since coal mine dust causes pneumoconiosis, it might be expected that an effect of dust on COPD would be reflected in a higher risk of obstructive lung disease in men with pneumoconiosis. However, it must be remembered that pneumoconiosis is only a crude marker for dust exposure. Moreover, the effects of dust on risk of pneumoconiosis and COPD might not be independent. It is possible, for example, that individuals differ in their response to dust, some tending to develop fibrosis and others airways obstruction. Also, the different geographical distributions of mortality from pneumoconiosis and COPD in miners suggest that their relation to dust is not identical.

Another potential source of error in the mortality studies is confounding by nonoccupational exposures. Some of the studies which found increased mortality from COPD in miners compared with non-miners did not include data on smoking, although this is a major cause of the disease. However, the absence of any corresponding excess of lung cancer suggests that miners are not unusually heavy smokers. The possibility of other unrecognised confounding cannot be completely ruled out, but it is unlikely that such confounding would have a major impact, particularly in the PFR study which compared mortality within a group of miners according to their dust exposure.

Overall, the findings of the mortality studies are remarkably consistent, both with each other and also with the studies of respiratory symptoms and lung function in miners.

\section{Emphysema in coal miners at necropsy}

Several studies have assessed the prevalence or severity of emphysema at necropsy in coal miners, either in comparison with other occupations or in relation to estimated dust exposure. Cockcroft and colleagues carried out a post-mortem survey of 38 coal miners and 48 non-coal miners aged 50-70 years who died in South Wales. ${ }^{31}$ All lungs were examined in a standardised way, and the extent of centrilobular and panacinar emphysema was scored on 
numerical scales. The emphysema observed was predominantly centrilobular with virtually no panacinar. After adjustment for age and smoking habits (obtained from relatives or from the Department of Health and Social Security Pneumoconiosis Panel), emphysema was more frequent in miners than in nonminers (odds ratio $10.35,95 \%$ CI 2.71 to 39.56). Furthermore, the severity of centrilobular emphysema in the miners was related to the amount of dust in simple foci in the lungs. Miners with PMF tended to have higher emphysema and dust scores, but those without PMF still had a clear excess of emphysema.

Ruckley and colleagues studied necropsy material from men in the PFR study. The findings in 500 lungs were published in $1984^{32}$ and these were later extended in a second report based on examination of almost 1400 lungs. ${ }^{33}$ The prevalence of emphysema was examined in 503 men and, after allowance for age and smoking, there was a clear association between the occurrence of centriacinar emphysema and the amount of dust to which a man had been exposed during his lifetime. However, this relation could only be demonstrated unequivocally for men whose lungs showed some dust-related fibrosis. Dust exposure was not associated with the occurrence of panacinar emphysema.

Leigh and colleagues examined the lungs of 264 out of 376 coal miners in New South Wales who died during 1966-83 and underwent necropsy. ${ }^{34}$ They estimated that necropsies were performed on some $20 \%$ of all miners who died during this period. Lungs were prepared and emphysema was quantified in a standardised manner. Pneumoconiosis was classified on the basis of macroscopic and microscopic examination of lung tissue and examination of whole lung sections, and in most subjects was minimal or mild. The coal content of lungs was measured. Smoking histories were obtained from standardised questionnaires at routine clinical examinations which had been held every two to three years. Emphysema score increased with the coal content of the lung, age and amount smoked, the relation with coal content being stronger in non-smokers than smokers.

These necropsy studies have various limitations. One concern is the extent to which the men studied were representative of miners more generally. For example, Ruckley noted that her necropsy cases included a higher proportion of men dying from bronchitis, emphysema and pneumoconiosis than the PFR population followed for mortality by Jacobsen. However, this on its own would not bias the findings. For bias to occur the samples of men studied would have to be unrepresentative in terms of the relation between dust and emphysema, which is perhaps less likely.

The studies by Cockcroft and Leigh included no direct data on dust exposure. In theory, an association between emphysema and coal content of the lung might occur not because dust causes emphysema, but because emphysema increases dust retention in the lung. However, this would not explain the association with dust exposure in the Ruckley study.

Another possibility is that associations with dust were confounded by other causes of emphysema. For example, the miners studied by Cockcroft may have differed from their non-mining controls in exposure to childhood respiratory infections, a known risk factor for later COPD. Such confounding is less likely, however, in the comparisons between miners with different levels of exposure to dust.

Despite their individual weaknesses, when viewed together these studies strongly suggest that coal dust causes emphysema, particularly but not necessarily exclusively in miners with pneumoconiosis.

\section{Toxicological investigations}

Observational studies in coal miners and experimental studies in animals chronically exposed to coal dust by inhalation have shown that retention of coal dust in the lungs is associated with the accumulation and activation of neutrophils and alveolar macrophages within alveoli. Rom ${ }^{35}$ compared bronchoalveolar lavage (BAL) findings in 17 coal miners who were non-smokers or ex-smokers (for more than five years) with those in 12 non-smokers and six current smokers of similar age who were not miners. All 17 coal miners had pneumoconiosis, 12 with simple coal workers' pneumoconiosis and five with progressive massive fibrosis. The coal miners had a higher proportion of neutrophils recovered at bronchoalveolar lavage than both the smoking and non-smoking controls, and all coal miners had an increased diffuse uptake of gallium-67 in their lung fields. Neutrophil elastase activity was increased in BAL fluid in coal miners, particularly in those with categories 2 and 3 simple pneumoconiosis, and their alveolar macrophages spontaneously released superoxide anion and hydrogen peroxide. In a subsequent study Rom found that macrophages recovered from individuals exposed to mineral dusts without radiographic or functional evidence of disease secreted significantly lower concentrations of superoxide anion and hydrogen peroxide than those with evidence of disease. ${ }^{36}$

Brown and Donaldson made similar observations in rats exposed to coal dust in a concentration of $10 \mathrm{mg} / \mathrm{m}^{3}$ in air for up to 52 days. ${ }^{37}$ Compared with controls, rats exposed to coal dust had a higher proportion of neutrophils recovered at BAL and significantly higher concentrations of neutrophil elastase activity were found in their BAL fluid.

These observations indicate that coal dust stimulates the recruitment of neutrophils to the lungs and both these neutrophils and resident alveolar macrophages show evidence of activation, secreting free radicals and proteolytic enzymes, plausible mediators of tissue injury in emphysema.

\section{Overview}

The research that has been reviewed helps to answer several questions. 
DOES COAL MINE DUST CAUSE LOSS OF LUNG FUNCTION?

Reductions in lung function have been found in relation to coal mining with remarkable consistency. The main exceptions to this are the most recent cross sectional survey from the PFR where loss of $\mathrm{FEV}_{1}$ was only associated with dust exposure at one of the three pits studied, ${ }^{11}$ the analysis by Seixas and colleagues which showed no dust related decline in $\mathrm{FEV}_{1}$ between the second and fourth rounds of the NSCWP in men who had entered the coal industry after $1969,{ }^{17}$ and the study of claimants for industrial injuries benefit by Stenton and colleagues. ${ }^{22}$ However, the anomalous findings of Stenton's group may have been a consequence of the way in which their sample of miners was selected, and the apparent discrepancies in the other two investigations could have occurred simply by chance.

Individually, all of the studies that have addressed the relation of coal mining to lung function have limitations, but these vary from one investigation to another and often would tend to obscure rather than exaggerate any effect of dust. The balance of evidence points overwhelmingly to impairment of lung function from exposure to coal mine dust, and this is consistent with the increased mortality from COPD that has been observed in miners.

IS THE LOSS OF LUNG FUNCTION CAUSED BY COAL MINE DUST DISABLING?

Morgan has argued that, whereas susceptibility to the adverse effects of smoking varies markedly between persons with a minority developing severe impairment of lung function while many others are relatively unaffected, the loss of $\mathrm{FEV}_{1}$ caused by coal mine dust is distributed much more evenly and is almost always minor. ${ }^{38} \mathrm{He}$ bases this theory in part on the observation that bronchitis is present in over $50 \%$ of non-smoking miners who have worked for 20 years or longer. Also, in a survey of 611 coal miners seeking compensation for "black lung" in the United States he and his colleagues found only one non-smoker who, in the absence of other non-occupational respiratory diseases, had sufficient airways obstruction to make hard labour difficult. ${ }^{1}$

These arguments are unconvincing, however. In their seminal longitudinal investigation into the natural history of COPD, Fletcher and colleagues found that the presence of chronic bronchitis had no independent influence on decline in $\mathrm{FEV}_{1}$ once other risk factors such as smoking had been taken into account. ${ }^{39}$ Thus, it is unclear why the prevalence of bronchitis in miners should be relevant to their susceptibility to loss of $\mathrm{FEV}_{1}$ from dust. The data on claimants for compensation cannot be interpreted without information about the population from which the study sample was derived, and about the number of non-smokers with disabling airways obstruction that would be expected in this population in the absence of dust exposure.

Against Morgan's theory is the clear increase in the prevalence of severe losses of lung function (to less than $65 \%$ predicted) that Marine found with higher dust exposures in the PFR population, ${ }^{10}$ and the excess mortality from COPD that has been recorded in miners compared with other occupations ${ }^{24} 28$ and in miners from the PFR with higher compared with lower dust exposures. ${ }^{29}$ These observations do not necessarily prove that the loss of $\mathrm{FEV}_{1}$ from dust is ever substantial. In a man who already had poor lung function for other reasons, a small additional loss of $\mathrm{FEV}_{1}$ from dust exposure might be sufficient to take him below the threshold of $65 \%$ predicted, or to tip the balance between survival and death from COPD. It would, however, be unusual to find no variation whatsoever in individual susceptibility to a toxic hazard. Either way, there is strong evidence that coal mine dust can have a critical influence on health in an important number of people.

BY WHAT MECHANISM DOES COAL MINE DUST CAUSE LOSS OF LUNG FUNCTION?

Exposure to coal mine dust is associated with symptoms of chronic bronchitis but, as already described, bronchitis of itself does not appear

Table 1 Estimated reductions in FEV associated with an exposure to coal mine dust of $1 \mathrm{ghm}^{-3}$

\begin{tabular}{|c|c|c|c|}
\hline Study & Type of analysis & Notes & $\begin{array}{l}\text { Reductions in FEV } \\
\text { ghm }^{-3} \text { ) }\end{array}$ \\
\hline Rogan et al (1973) ${ }^{7}$ & Cross-sectional & Current miners & 0.6 \\
\hline Love and Miller $(1982)^{8}$ & Longitudinal & $\begin{array}{l}\text { Extra loss over } 11 \text { years in relation to previous dust } \\
\text { exposure }\end{array}$ & 0.36 \\
\hline Attfield $(1985)^{14}$ & Longitudinal & $\begin{array}{l}\text { Extra loss over } 11 \text { years in relation to concurrent dust } \\
\text { exposure }\end{array}$ & $\star \star 1.6$ \\
\hline Soutar and Hurley $(1986)^{9}$ & Cross-sectional & Current and ex-miners & 0.76 \\
\hline Attfield and Hodous $(1992)^{15}$ & Cross-sectional & White males aged $25+$ years & 0.69 \\
\hline Seixas et al $(1992)^{16}$ & Cross-sectional & Miners who started work in or after 1970 & $\star 3.4$ \\
\hline Seixas et al $(1993)^{17}$ & Longitudinal & $\begin{array}{l}\text { Miners who started work in or after } 1970 \text {. Extra loss } \\
\text { over } 11 \text { years in relation to previous dust exposure } \\
\text { Miners who started work in or after } 1970 \text {. Extra loss } \\
\text { over } 11 \text { years in relation to concurrent dust exposure }\end{array}$ & $\begin{array}{l}\star-4.8 \\
\star-1.8\end{array}$ \\
\hline Soutar et al $(1993)^{11}$ & Cross-sectional & $\begin{array}{l}\text { South Wales } \\
\text { Yorkshire } \\
\text { NE England }\end{array}$ & $\begin{array}{l}1.04 \\
0.08 \\
-0.28\end{array}$ \\
\hline Henneberger and Attfield $(1996)^{18}$ & Longitudinal & $\begin{array}{l}\text { Miners who worked before } 1970 \text {. Extra loss over } 11 \\
\text { years in relation to previous dust exposure } \\
\text { Miners who worked before } 1970 \text {. Extra loss over } 11 \text { years } \\
\text { in relation to concurrent dust exposure }\end{array}$ & ${ }^{\star} 0.48$ \\
\hline Carta et al $(1996)^{20}$ & Longitudinal & $\begin{array}{l}\text { Extra loss over } 11 \text { years in relation to previous dust } \\
\text { exposure } \\
\text { Extra loss over } 11 \text { years in relation to concurrent dust } \\
\text { exposure }\end{array}$ & $\begin{array}{l}\star-9.6 \\
\star 4.8\end{array}$ \\
\hline
\end{tabular}

${ }^{\star}$ Calculated by us from the published results with the assumption that a miner works for 1600 hours per year. 
to cause detectable loss of $\mathrm{FEV}_{1}$. The explanation for the impairment of lung function in coal miners is therefore likely to lie elsewhere.

Studies based on post-mortem examination of lungs suggest that coal mine dust can cause centrilobular emphysema, especially when pneumoconiosis is present, but perhaps also in other situations. ${ }^{31-34}$ This is plausible given the experimental evidence that inhalation of dust from mines causes release of inflammatory mediators by neutrophils. ${ }^{35}$ However, we cannot be certain that this is the only or even the main mechanism whereby lung function is lost. Another possibility is that dust causes inflammation of the small airways, although there is little direct evidence for this.

Further clues may lie in the pattern of lung function deficit associated with dust exposure. There is some indication that the loss of FVC relative to $\mathrm{FEV}_{1}$ is greater from dust than from smoking. ${ }^{9}$ At present, however, the exact nature of the pathology underlying the loss of lung function in miners is still uncertain.

HOW DOES LOSS OF LUNG FUNCTION RELATE TO THE AMOUNT OF DUST EXPOSURE?

This question is relevant to the setting of occupational exposure standards and also to compensation. It is complicated by the need to take account of smoking and other nonoccupational sources of variation in lung function. In addition, problems arise from inevitable inaccuracies in the exposure assessments on which risk estimates have been based. As already discussed, these would normally be expected to attenuate exposure-response relations, but the extent of the bias is uncertain.

Most of the available data relate to effects on $\mathrm{FEV}_{1}$, but the steepness of the decline in $\mathrm{FEV}_{1}$ with a given exposure has varied between studies (table 1). One reason for this variation is likely to be differences in the impact of biases, such as from inaccurate exposure assessment, but other factors may also contribute.

There could be genuine differences in the susceptibility of people to dust, with those who are most sensitive tending to leave the coal industry before normal retirement age. This would lead to less steep exposure-response relations in studies based on survivor populations who remain in coal mining. However, it is notable that the estimated effect of dust in Rogan's study, ${ }^{7}$ which focused on a survivor population, was similar to that from the analysis of Soutar and Hurley ${ }^{9}$ which included men who had left the industry as well as others who were still employed as miners.

Another possibility is effect modification by factors that vary geographically. For example, differences in diet or in exposure to respiratory infections during infancy might alter the response of the lung to dust. Geological differences could also be relevant, although mortality data suggest that, within England and Wales, the risk of COPD in miners varies much less between coal fields than that of pneumoconiosis. ${ }^{30}$

On theoretical grounds the study by Soutar and Hurley ${ }^{9}$ is probably the most reliable of the cross sectional analyses. It uses the best data on exposure and includes both current and ex-miners. Furthermore, the estimated effect of dust (a loss of $0.76 \mathrm{ml}$ per $\mathrm{ghm}^{-3}$ ) was reasonably robust to the way in which smoking was included in the analysis. When allowance is made for random sampling variation, most of the other cross sectional surveys have found dust effects that would be compatible with this estimate.

The longitudinal studies of lung function in miners have tended to produce less clearcut results. Some have found associations between decline in $\mathrm{FEV}_{1}$ and previous cumulative exposure to dust, suggesting that the effect of dust on lung function is not all immediate. But only one has shown a statistically significant relation with concurrent dust exposure. ${ }^{20}$ This lack of statistical significance may simply reflect a greater impact of random measurement error in longitudinal studies where the real differences between subjects are much smaller than in cross sectional investigations. Although not all statistically significant, the results of the longitudinal studies are again generally compatible with Soutar and Hurley's estimate for the effect of dust.

The combined effects of coal mine dust and smoking on $\mathrm{FEV}_{1}$ appear to be additive.
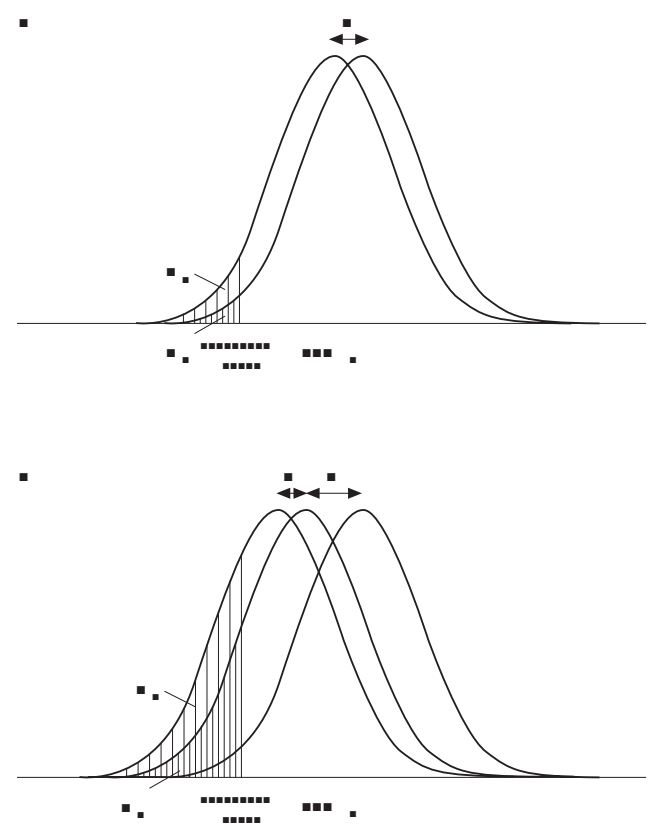

Figure 1 Combined effects of smoking and dust on the risk of FEV falling below a specified threshold. It is assumed that FEV $V_{1}$ is normally distributed in the population and that a given cumulative exposure to dust shifts the distribution downwards by a decrement " $d$ ". In the absence of smoking $(A)$ the relative risk of having an $F E V_{1}$ below a threshold value as a consequence of this dust exposure is given by the ratio of areas under the curves $\left(P_{0}\right.$ $\left.+P_{\nu}\right) / P_{0}$. If it is assumed that a given cumulative exposure to tobacco smoke causes an additional downward shift in the distribution of $F E V_{1}$ by a decrement " $s$ ", and that the effects of dust and smoking on $F E V_{1}$ are additive, the position will be as depicted in $B$. The relative risk of having an FEV below the threshold is again given by $\left(P_{0}+\right.$ $\left.P_{\nu}\right) / P_{0}$. As age increases, cumulative exposure to tobacco smoke among smokers also increases and so too does the decrement " $s$ " attributable to smoking. The effect is a reduction in the ratio $\left(P_{0}+P_{1}\right) / P_{0}$. Thus, the relative risk of having an FEV, below the threshold as a consequence of a given cumulative dust exposure would be expected to decline with age in smokers. 
No study has found any significant interaction beyond this. Marine's analysis indicated a multiplicative effect of smoking and dust on the risk of dichotomous end points such as having an $\mathrm{FEV}_{1}$ less than $65 \%$ predicted,${ }^{10}$ but this is quite compatible with an additive effect on $\mathrm{FEV}_{1}$.

Another feature of the Marine analysis was a negative interaction between dust and age in smokers. For a given cumulative exposure to dust, the risk of most of the end points studied was lower at older ages. With an additive effect of dust and smoking on lung function, a pattern of this sort might be expected. At older ages smokers have lost more lung function relative to non-smokers than when younger (because they have been smoking for longer). Therefore, the relative impact of a specified cumulative exposure to dust will be less (fig 1). In addition, the older miners in the Marine analysis would have acquired a greater part of their exposure to dust in the years before the PFR began. This exposure had to be estimated by extrapolation and would not have been assessed so accurately as that which occurred later. The resultant bias may therefore have caused a greater attenuation of dust effects in the older men, and thereby increased the negative interaction between dust and age. It could also have contributed to the apparently smaller effect of dust on $\mathrm{FEV}_{1}$ at older ages in Rogan's study. ${ }^{7}$

It is difficult to know whether any negative interaction between cumulative dust exposure and age would remain if biases from measurement error could be eliminated. If it did, this might indicate a more than linear response to increasing intensity of exposure, or perhaps a larger effect from early than late exposure. In the absence of further empirical data, however, it seems reasonable to take Soutar and Hurley's figure of $0.76 \mathrm{ml}$ per $\mathrm{ghm}^{-3}$ as a best estimate of the average loss of $\mathrm{FEV}_{1}$ from dust exposure in coal miners.

1 Lapp NL, Morgan WKC, Zaldivar G. Airways obstruction, coal mining, and disability. Occup Environ Med 1994;51:234-8

2 Higgins ITT, Oldham PD. Ventilatory capacity in miners. $\mathrm{Br}$ f Ind Med 1962;19:65-76.

3 Lloyd MH, Gauld SJ, Soutar CA. Respiratory ill health among coal miners and telecommunication workers in South Wales. Br F Ind Med 1986;43:177-81.

4 Nemery B, Brasseur L, Veriter C, et al. Impairment of ventilatory function and pulmonary gas exchange in nonsmoking coalminers. Lancet 1987;1427-30.

5 Lewis S, Bennett J, Richards K, et al. A cross sectional study of the independent effect of occupation on lung function in British coal miners. Occup Environ Med 1996;53:125-8.

British coal miners. Occup Environ Med 1996;53:125-8.
6 Rae S, Walker DD, Attfield MD. Chronic bronchitis and Rae S, Walker DD, Attfield MD. Chronic bronchitis and
dust exposure in British coalminers. In: Walton WH, ed. dust exposure in British coalminers. In: Walton WH, ed.
Inhaled particles III. Old Woking, Surrey: Unwin, 1971: Inhaled par

7 Rogan JM, Attfield MD, Jacobsen M, et al. Role of dust in the working environment in development of chronic bronchitis in British coal miners. Br F Ind Med 1973;30:217-26.

8 Love RG, Miller BG. Longitudinal study of lung function in coal-miners. Thorax 1982;37:193-7.

9 Soutar CA, Hurley JF. Relation between dust exposure and lung function in miners and ex-miners. Br F Ind Med 1986; 43:307-20.

10 Marine WM, Gurr D, Jacobsen M. Clinically important effects of dust exposure and smoking in British coal miners. Am Rev Respir Dis 1988;137:106-12.
11 Soutar C, Campbell S, Gurr D, et al. Important deficits of lung function in three modern colliery populations: relations with dust exposure. Am Rev Respir Dis 1993;147: 797-803.

12 Hurley JF, Burns J, Copland L, et al. Coalworkers' simple pneumoconiosis and exposure to dust at 10 British coalmines. Br f Ind Med 1982;39:120-7.

13 Morgan WKC, Handelsman L, Kibelstis J, et al. Ventilatory capacity and lung volumes of US coal miners. Arch Environ Health 1974;28:182-9.

14 Attfield MD. Longitudinal decline in $\mathrm{FEV}_{1}$ in United States coalminers. Thorax 1985;40:132-7.

15 Attfield MD, Hodous TK. Pulmonary function of US coal miners related to dust exposure estimates. Am Rev Respir Dis 1992;145:605-9.

16 Seixas NS, Robins TG, Attfield MD, et al. Exposureresponse relationships for coal mine dust and obstructive lung disease following enactment of the Federal Coal Mine Health and Safety Act of 1969. Am f Ind Med 1992;21:715-34.

17 Seixas NS, Robins TG, Attfield MD, et al. Longitudinal and cross sectional analyses of exposure to coal mine dust and pulmonary function in new miners. Br F Ind Med 1993;50: 929-37.

18 Henneberger PK, Attfield MD. Coal mine dust exposure and spirometry in experienced miners. Am $\mathcal{F}$ Respir Crit Care Med 1996;153:1560-6.

19 Comptroller General of the United States. Report to Congress. Improvements still needed in coal mine dustsampling program and penalty assessment and collections. Washington DC: Departments of the Interior and Health, Washington DC: Departments of the Interior
Education, and Welfare, 1975 (RED-76-56).

20 Carta P, Aru G, Barbieri MT, et al. Dust exposure, respiratory symptoms, and longitudinal decline in lung function in young coal miners. Occup Environ Med 1996;53:312-9.

21 Oxman AD, Muir DCF, Shannon HS, et al. Occupational dust exposure and chronic obstructive pulmonary disease. Am Rev Respir Dis 1993;148:38-48.

22 Sandhu PS, Bourke SJ, Hendrick DJ, et al. The effects of cigarette smoking and duration of work on the lung function of coal miners. Thorax 1996; 51(Suppl 3):A43

23 Liddell FDK. Mortality of British coal miners in 1961. Br f Ind Med 1973;30:15-24.

24 Rockette HE. Cause specific mortality of coal miners. $\mathcal{F}$ Occup Med 1977;19:795-801.

25 Cochrane AL, Haley TJL, Moore F, et al. The mortality of men in the Rhondda Fach 1950-1970. Br f Ind Med 1979; 36:15-22.

26 Cochrane AL, Moore F. A 20-year follow-up of men aged 55-64 including coal-miners and foundry workers in Staveley, Derbyshire. Br F Ind Med 1980;37:226-9.

27 Cochrane AL, Moore F. A 20 -year follow-up of a population sample (aged 25-34) including coal-miners and foundry workers in Staveley, Derbyshire. Br f Ind Med 1980;37: 230-3.

28 Atuhaire LK, Campbell MJ, Cochrane AL, et al. Mortality of men in the Rhondda Fach 1950-80. Br F Ind Med 1985; 42:741-5.

29 Miller BJ, Jacobsen M. Dust exposure, pneumoconiosis and mortality of coalminers. Br F Ind Med 1985;42:723-33.

30 Coggon D, Inskip H, Winter P, et al. Contrasting geographical distribution of mortality from pneumoconiosis and chronic bronchitis and emphysema in British coal miners. Occup Environ Med 1995;52:554-5.

31 Cockcroft A, Wagner JC, Ryder R, et al. Post-mortem study of emphysema in coalworkers and non-coalworkers. Lancet 1982;ii:600-3.

32 Ruckley VA, Gauld SJ, Chapman JS, et al. Emphysema and dust exposure in a group of coal workers. Am Rev Respir Dis 1984;129:528-32.

33 Ruckley VA, Fernie JM, Campbell SJ, et al. Causes of disability in coalminers; a clinico-pathological study of emphysema, airways obstruction and massive fibrosis. Report No. TM/89/05. Edinburgh: Institute of Occupational Medicine, 1989.

34 Leigh J, Driscoll TR, Cole BD, et al. Quantitative relation between emphysema and lung mineral content in coalworkers. Occup Environ Med 1994;51:400-7.

35 Rom WN. Basic mechanisms leading to focal emphysema in coal workers' pneumoconiosis. Environ Res 1990;53:16-28.

36 Rom WN. Relationship of inflammatory cell cytokines to disease severity in individuals with occupational inorganic dust exposure. Am f Ind Med 1991;19:15-27.

37 Brown GM, Donaldson K. Inflammatory responses in lungs of rats inhaling coalmine dust: enhanced proteolysis of fibronectin by bronchoalveolar leukocytes. Br f Ind Med 1989;46:866-72.

38 Morgan WKC. On dust, disability and death. Am Rev Respir Dis 1986;134:639-41.

39 Fletcher C, Peto R, Tinker C, et al. The natural history of chronic bronchitis and emphysema. Oxford: Oxford University Press, 1976. 